\title{
Crossing Boundaries and Bridging Gaps: Thoughts on Relationships Between Ethnomusicology And Music Psychology
}

\author{
MARTIN CLAYTON \\ Department of Ethnomusicology, Open University, Walton Hall
}

\begin{abstract}
Judith Becker's contribution highlights the timely issue of interdisciplinary interaction between ethnomusicology and music psychology, with its attendant opportunities and difficulties. My response aims to first of all place this issue in the historical context of disciplinary development and differentiation. As for the present-day situation, I argue that for interdisciplinary engagement to be productive, bridges need to be built between pockets of interest on both sides of the disciplinary divide. The difficulties faced by Becker do not in my view suggest that there is no appetite on the psychology side of the divide for interdisciplinary exchange, although they do highlight some of the barriers to such communication.
\end{abstract}

Submitted 2009 May 27; accepted 2009 June 3.

KEYWORDS: ethnomusicology, psychology of music, interdisciplinary, ideology, research

JUDITH Becker's highlighting of the disciplinary gap between ethnomusicology and the psychology of music is timely, coming at a historical moment when not only is this particular gap being investigated by a number of researchers, but the relationships between all academic disciplines concerned with music are in a state of flux. As an ethnomusicologist who has been fascinated for many years by psychological approaches, and who has contributed to publications aimed at psychologists, I offer my thoughts here on the general issues raised by the author, with some reflections both on this particular case study and on some of my own work below.

\section{ETHNOMUSICOLOGY AND MUSIC PSYCHOLOGY: RELATIONS IN HISTORY AND THE PRESENT DAY}

First, it may be instructive to briefly historicize this disciplinary relationship, since the two disciplines were extremely closely related for a period spanning the last quarter of the nineteenth century and the first quarter of the twentieth. Key figures in the emergence of ethnomusicology's predecessor comparative musicology such as Carl Stumpf, Erich von Hornbostel and Charles Myers were regarded, and regarded themselves, as psychologists: Myers for instance, arguably Britain's most significant comparative musicologist, went on to write a standard textbook in experimental psychology. The boundaries between the comparative study of music - generally written from an evolutionist perspective - and the comparative study of the perception of tone (or, to cite a parallel interest of Myers's, colour) were fluid, to say the least.

This is not the place for a full discussion of the reasons for subsequent separation between the two disciplines, but on the side of ethnomusicology, we can point to a rejection of evolutionism and with it, to a great extent, both comparativism and scientific method; and on the side of psychology, we can identify a retreat from a concern with mankind as a whole into the culture of the university laboratory.

One of the reasons why generalisation is dangerous, however, is that both ethnomusicology and music psychology remain both pluralistic and inherently interdisciplinary. Ethnomusicologists mostly find themselves in music faculties, working alongside musicologists, and yet feel at least as much in common with anthropologists and other social scientists. Although Becker is right to point to an often violent rejection 
of scientific method, often on ideological grounds, it remains true that a significant number of professional ethnomusicologists are not only sympathetic to scientific and experimental approaches, but can claim proficiency in these methods through their own training (the names Udo Will and John Baily spring immediately to mind).

If ethnomusicologists feel themselves split between humanities and interpretative social sciences, psychologists can point to a similar divide between the 'hard' and social sciences; a good proportion of music psychology is also carried out within music faculties, again under a broad 'humanities' umbrella. Approaches of music psychologists appear, from an interested outsider's perspective, to vary widely from the experimental and quantitative to the interpretative and frankly humanistic. This complicates the humanitiesscience binary, although up to a point it remains useful to consider the disciplinary divide on these simplified terms. The sense of existing on and between boundaries, and of living a marginal academic existence, is therefore something ethnomusicologists and music psychologists share.

A profound ideological gap is sometimes hinted at by ethnomusicology's most outspoken opponents of positivistic scientific method, one that would certainly stand in the way of deeper dialogue between the disciplines. I am not convinced, however, that such a clear ideological divide exists in reality. The gap (which undeniably does exist) is that between research paradigms, separating an approach that produces knowledge through an inductive and interpretative process involving close engagement with musicians within their own cultural context, from approaches that advance knowledge incrementally through controlled, decontextualised laboratory study and statistical standards of proof. If psychologists see much ethnomusicological writing as lacking in rigour, where preferred interpretations are not always subjected to critical evaluation, I believe that ethnomusicologists should learn from the critique. Similarly, when ethnomusicologists argue that in controlling variables and taking music out of context, psychologists often study a phenomenon that bears little relationship to actual musical behaviour, psychology ought to take that critique seriously too.

The arguments for greater dialogue between our two disciplines are easy enough to make: we are both concerned with the same topic, and at a high level with many of the same questions: why do people make music, and how do they make sense of it? While there may be positive reasons for maintaining the integrity of disciplines, where these boundaries prevent communication between scholars investigating the same subject matter, something is clearly wrong. In order to dig deeper into this issue, though, we need to look at specific case studies.

\section{The case of trance and the case of entrainment}

Trance is an excellent example with which to interrogate the ethnomusicology-psychology divide. On the one hand, trancing is a widespread phenomenon which occurs in quite specific cultural contexts, often associated with religious rituals, and is interpreted by its practitioners within the frame of those practices: it therefore requires us both to take seriously the subjective testimony of individual participants, and to take into account the ways in which the broader ritual contexts guide and constrain this discourse. On the other hand, trance is associated with both distinctive behaviours and reports of altered states of consciousness: if the latter are not to be dismissed as the inventions of untrustworthy informants, then something is happening in a psychophysiological sense which is clearly worthy of serious investigation.

Unfortunately, what so far appears to be a happy and potentially productive state of affairs is complicated by at least two further factors. For one, the very fact that trancing is embedded in specific ritual contexts means that it is particularly difficult to learn anything useful about the subject in a laboratory situation, while considerable thought would need to be given to investigating it in context, even assuming that participants were willing to be 'investigated' at such deeply meaningful and highly-charged moments. As if that were not enough, I expect Becker is right to identify an unease on the part of her scientific reviewers with the whole idea of investigating trance states: the fear of association with pseudo-scientific mumbo-jumbo is doubtless enough of a motivation for many to wish the subject away.

With the benefit of hindsight, Becker and Joshua Penman's endeavour looks almost bound to fail as an exercise in bringing ethnomusicology and psychology together, since it not only takes psychology into the realm of ethnography and culture but also tackles a subject - trance - that appears little short of taboo to the scientific community: the latter issue may, in fact, be a more intractable problem then that of disciplinecrossing per se. What the project would need in order to succeed fully, perhaps, is a link to a robust body of work on the psychological side of the fence dealing with trance experiences; if this could be established then 
one might hope to succeed in bridging a gap between two bodies of literature, whereas what we see here is an attempt to bridge from ethnomusicology to nothing.

My colleagues and I have benefited from a more sympathetic environment in writing about the topic of entrainment within an ethnomusicological context (Clayton, Sager and Will, 2005). In 2007 I discussed temporal coordination between Indian musicians, in a paper written in scientific terms for a scientific journal, albeit one with an inbuilt sympathy to interdisciplinary approaches. Thanks to the guidance of Udo Will in particular, I was able to cross the great divide and publish on 'scientific' terms. But I think the reason that I was able to do this and Becker and Penman were not - in this case at least - is that in my case my approach to entrainment was profoundly influenced by an established body of psychological literature, primarily Mari Riess Jones's dynamic attending theory; having adopted this theory and applied it in an ethnomusicological context, the challenge of framing my findings for a scientific audience was that much more tractable.

\section{CONCLUSIONS}

In summary, I believe that it is far from impossible for individual researchers to cross the divide from ethnomusicology to music psychology. The challenge of individually crossing disciplinary boundaries is, however, a relatively trivial one. The bigger challenge, surely, is to make discipline speak to discipline on a larger scale: in the case of our entrainment studies, is it possible to persuade a scientific community that the programme of work which they hold dear can be pursued in a more productive way by drawing on ethnographic studies and real-world data? I believe that this is possible, but we have achieved relatively little to date. Conversely, is it possible for researchers of a scientific disposition to persuade ethnomusicologists that some of the questions that interest them can in fact be answered, or partially answered, through controlled empirical studies? Again, I believe that this is possible, but again, little has been achieved to date: ethnomusicologists have in fact been rather fond of dismissing attempts to explain their data using statistical models.

Where disciplines remain attached to their own epistemological superiority, and unwilling to compromise and combine forces with those of different views, disciplinary divides will only widen to the detriment of all. On the other hand, when scholars learn enough of each others' research paradigms and epistemologies to appreciate the kinds of knowledge that their colleagues seek, they will find points of common interest: these points represent a narrowing of the interdisciplinary chasm, points at which bridges can be built.

What the longer term prospects are is harder to say. Some differences, as Becker suggests, are bound to remain: we have little to gain from academic work that, in seeking to speak to all, satisfies no-one's criteria for worthwhile knowledge. On the other hand, disciplines are not forever: they can and do constantly split and recombine. What we have to gain from a sustained interdisciplinary dialogue is the development of a body of scholars who have a broad understanding of different forms of knowledge about music and the relations between them; and also an academy in which disciplinary boundaries are constantly under negotiation, and in which productive new approaches can flourish, rather than be stifled because they do not fit with prevailing models.

\section{REFERENCES}

Clayton, M., Sager, R. \& Will, U. (2005) In time with the music: the concept of entrainment and its significance for ethnomusicology, European Meetings in Ethnomusicology 11 (ESEM Counterpoint 1), 3-75.

Clayton, M. (2007) Observing entrainment in music performance: video-based observational analysis of Indian musicians' tanpura playing and beat marking, Musicae Scientiae, 11(1): 27-60. 